\title{
ZONIFICACIÓN GEOECOLÓGICA, UN CRITERIO PARA LA INTERPRETACIÓN Y EL ANÁLISIS ESPACIAL DEL PAISAJE URBANO DE LA CIUDAD DE MORELIA
}

\author{
Ayesa Martínez Serrano \\ Centro de Investigación en Geografía Ambiental. Universidad Nacional Autónoma de México. Campus Morelia \\ amartinez@pmip.unam.mx
}

\section{RESUMEN}

La creciente necesidad de análisis del proceso de urbanización, demanda desarrollo teórico-metodológico y sistémico. La comprensión geoecológica del espacio expresa la interrelación entre paisajes naturales y factores antropogénicos. Se plantea un procedimiento metodológico multiescalar que integra la evaluación del paisaje físico-geográfico y las formas sociales de ocupación. Se realiza el análisis de las unidades físico-geográficas, mediante la interpretación del modelo sombreado del terreno. Se establece la identificación y caracterización del uso y la cobertura terrestre, a través del procedimiento matricial y la descripción de 247 unidades. Luego del análisis cuantitativo y cualitativo multivariable se realiza la zonificación geoecológica en el paisaje urbano.

Palabras claves: Geoecología, interfase periurbana, ciudad, urbano, zonificación, análisis espacial.

\section{ABSTRACT}

The growing need for analysis of the process of urbanization, requires the theoretical and methodological development and systemic. The geo-ecological comprehension of space, expresses the interrelationship between landscapes natural and factors anthropogenic. The proposal contains one methodological multiscalar procedure that integrates physical-

Fecha de recepción: junio 2015.

Fecha de aceptación: marzo 2016. 
geographical landscape and social forms of occupation. The analysis of the physicalgeographical units, is performed with the construction of shaded terrain model. The characterization establishes the identification of use and land cover, the matrix procedure and its description of 247 units. After multivariate analysis it is performed the geo-ecological zoning of the urban landscape.

Keywords: Geoecology, peri-urban interface, city, urban, zoning, spatial analysis.

\section{INTRODUCCIÓN}

En las últimas décadas el abordaje geográfico del paisaje es objeto de estudio a partir de diferentes enfoques, lo que implica que exista de manera paralela una diversidad de significados; complejo natural o geocomplejo (Solntsev, 1948), geosistema (Sochava, 1972, 1978; Arcia, 1994), landschaft (De Bolós, 1992), paisaje geográfico (Mateo et al., 1994; García y Muñoz, 2002), landscape (Turner et al., 2001; Burel et al., 2003), unidades ambientales biofísicas (López y Villers, 1995; Castillo, 2006), además siempre se hace referencia a su estrecha relación con manifestaciones externas, que corresponden al ámbito humano. Según esta perspectiva, el término de paisaje es la morfología o la expresión formal del espacio y de los territorios y refleja la visión que la población tiene sobre su entorno. De esta manera se concibe al paisaje como un sistema integral y complejo en la interfase naturaleza-sociedad, que toma en consideración la existencia de una estructura y un funcionamiento propio de los cuerpos naturales, que es determinado por el sistema de producción económica y cultural de acuerdo a los grupos sociales dominantes, siendo espacios naturales que la sociedad transforma para producir y habitar.

En la actualidad, más que como un concepto individual, el paisaje se considera un sistema de conceptos, es decir, el concepto de paisajes se ha transformado en la medida que la Sociedad interacciona con la Naturaleza. Para cada nivel de interacción se redefine el contenido del concepto paisaje. Así, se identifican diversas interpretaciones o acepciones del concepto de paisaje, de acuerdo al nivel de interrelaciones entre la Naturaleza y la Sociedad; el Paisaje Natural, el Paisaje Antropo-Natural, el Paisaje Social, el Paisaje Cultural, y el Paisaje Visual o Percibido (Bollo y Hernández, 2008). Entre la infinidad de formas y tipos de paisaje que se puedan diferenciar, el paisaje urbano (antrópico o antropogénico) es aquel que tiene el mayor grado de transformaciones de los recursos naturales, y se encuentra en constante cambio paralelo al desarrollo de la ciudad. Siguiendo esta línea hay que tomar en cuenta la forma de la ciudad en su marco natural y su función interna y dinámica por consiguiente, se debe interpretar el paisaje urbano desde dos direcciones; una externa que es la de la ciudad en relación con la región geográfica donde está ubicada, y otra interna que es la ciudad como sistema interurbano (Lucio y Gutiérrez, 2011). Es así, que la concepción del paisaje urbano se sostiene en el carácter holístico e integral de la ciencia del paisaje, desde su definición en la categoría específica de geosistema, los sistemas geoecológicos.

Las ciudades crecen continuamente y absorben antiguos espacios rurales, por lo que alteran sus condiciones ambientales y construyen nuevos escenarios urbanos. De este modo, el espacio urbano se considera diverso en dos direcciones principales; tanto en los flujos que en el conflu- 
yen como en su paisaje, específicamente en las zonas o franjas que se integran en su entorno (Rivera, 2013). Esto genera una nueva población urbana, que implica un proceso de ocupación espacial, lo cual de alguna manera está relacionado con el espacio o paisaje físico-geográfico que sirve de base a la producción de las inmobiliarias, los actores del gobierno y la variable cultural que interviene en la construcción social del mismo espacio. El proceso de urbanización es uno de los procesos antropogénicos que modifica con más intensidad a los paisajes físicogeográficos, lo hace de manera diferenciada y con desigual intensidad; los tipos de uso y las clases de cobertura resultantes de este proceso en el tiempo, son variados y complejos y tienen una relación directa con la estructura físico-geográfica del paisaje en los espacios modificados. La cobertura terrestre y el uso del suelo de un territorio surgen de las funciones que el hombre le asigna al espacio, resultado de sus necesidades de hábitat, explotación de recursos, etc.

Por su parte, la concepción científica general de la Geoecología de los Paisajes se presenta como una metodología de gran eficiencia y flexibilidad, que posibilita investigar y profundizar en el estudio de los paisajes de forma compleja e integral, de gran utilidad para las medidas de ordenamiento y planificación ambiental. Esta ciencia;... "Se concibe como un sistema de métodos, procedimientos técnicas de investigación, cuyos propósitos consisten en la obtención de un conocimiento sobre el medio natural, con los cuales se pueden establecer un diagnóstico de un estado operativo. A partir de ello, y sobre la base de evaluar el potencial de los recursos, es posible formular la estrategia de optimización de los usos y los manejos más adecuados"... (Mateo, 1991: 5). Así, el enfoque geoecológico para el estudio del territorio podría convertirse en un criterio básico y complementario para la interpretación y el análisis espacial del paisaje urbano y en proceso de urbanización, de esta manera se genera información básica y esencial para la elaboración de programas de desarrollo económico y social.

El presente trabajo forma parte de una investigación de Doctorado para la evaluación geoecológica de la situación ambiental en paisajes urbanizados. Por ello, el objetivo al que se le da cumplimiento en esta aplicación es la interpretacion, caracterización y el análisis espacial de áreas urbanas y en proceso de urbanización, mediante la adaptación del enfoque geoecológico. Con ello se busca generar una herramienta metodológica para la descripción y subdivisión del paisaje al interior de la ciudad y periferias, que contribuya a la obtención de información espacial a nivel local, y principalmente que interprete el paisaje urbanizado desde su base físico-geográfica en combinación con las formas antrópicas de apropiación del mismo, para comprobar las relaciones de subordinación entre estos aspectos en la proliferación de problemáticas ambientales. Esta propuesta se inserta en las bases de la concepción de la Geografía del paisaje y específicamente la evaluación geoecológica del paisaje que comprende el análisis de la morfología físico-geográfica del espacio y las formas sociales y funcionales producto de la actividad antrópica, y no se tienen en cuenta elementos del paisaje cultural que implica la percepción y el valor patrimonial del espacio por ser parte de la segunda fase de análisis en posteriores trabajos.

\section{I.1. El proceso de urbanización, sus efectos en el paisaje y la problemática para su delimitación}

Las ciudades en el mundo entero han desarrollado un ritmo de crecimiento notable. Este proceso de desarrollo de las ciudades y de concentración de la población en los núcleos urbanos se le ha nombrado por la comunidad científica urbanización. La urbanización 
implica la transformación de un espacio natural o rural en un espacio urbano. Este proceso ha provocado en los últimos decenios tanto un incremento del número de ciudades, como un incremento del número de personas que viven en ellas. A pesar de que la tendencia es el incremento de estos núcleos urbanos, este fenómeno se ha modificado a lo largo de los últimos años, por lo que se aprecia también la salida de población y de actividades desde las ciudades hasta el medio rural circundante, más o menos próximo, recibiendo población desde ellas, donde predomina el espacio no urbanizado, a este proceso se le identifica de manera general periurbanización (Ávila, 2009). Esto conlleva la generación de problemáticas urbanas, la construcción y mejora de infraestructuras, una nueva imagen de lo rural, incremento de los equipamientos públicos y de los servicios privados, y la elevación del nivel de renta. Contribuye a la aparición de numerosas áreas de viviendas unifamiliares de baja densidad en áreas aisladas, a la formación de nuevos barrios de viviendas continuas en el perímetro de núcleos rurales, rehabilitación de viviendas rurales dispersas o en el interior de los pueblos y también facilita la expansión numérica de las segundas residencias y la modificación de muchas de ellas en viviendas principales.

Las ciudades mexicanas adolecen de un constante crecimiento urbano que se manifiesta en la generación y expansión de las zonas metropolitanas, bajo un desarrollo acelerado y desordenado de las ciudades medias. Este crecimiento trae consigo la incorporación de tierras agrícolas como soporte de las nuevas actividades de carácter urbano. Este proceso propicia la conurbación resultado de las transformaciones territoriales. Lo que implica que los territorios de menor jerarquía son absorbidos por los requerimientos de las ciudades y se integran a su dinámica bajo formas muy diversas (Hernández et. al, 2009). Este modelo de crecimiento propicia la existencia de las periferias metropolitanas expandidas como los espacios alrededor de las áreas de la metrópoli y donde se manifiesta la influencia directa de la gran ciudad sobre la transformación tanto de áreas agrícolas como áreas deshabitadas de muy bajo o nulo valor productivo, que no mantienen un patrón continuo sino que puede ser disperso y fraccionado en la suma de estas formas territoriales, por lo que no tienen límites geográficos bien definidos.

Es importante entonces, conceptualizar los dos extremos de este proceso de periurbanización: el espacio urbano y el espacio rural. La definición de espacio urbano y rural resulta difícil y circular porque la definición de uno se hace por defecto con el otro. El espacio rural ha evolucionado mucho sobre todo tras los últimos modelos de crecimiento urbano emergentes. No obstante, en la literatura especializada (Carrasco y Albertos, 2014; Badia et. al., 2010; Zuluaga, 2005; Borruso, 2003; Binimelis, 2000; Adell, 1999) los rasgos característicos de estos espacios para diferenciarlos son típicamente dos: el poblacional y el funcional. A los fines de realizar su caracterización, se suelen considerar criterios cuantitativos o cualitativos. Los espacios o áreas urbanas suelen ser definidos previamente por criterios numéricos de población. Por otro lado, pueden aplicarse criterios cualitativos y cuantitativos funcionales como que el sector económico dominante no sea el primario, sino el sector secundario ciudad industrial o los servicios, entre otros. El espacio o área rural es el territorio no urbano de la superficie terrestre o parte de una división territorial que no está clasificada como área urbana o de expansión urbana: son las áreas no urbanizadas al menos en su mayor parte o destinadas a la limitación del crecimiento urbano, utilizadas para actividades agropecuarias, agroindustriales, extractivas, de silvicultura y de conservación ambiental (Capel, 1975, 2002). 
Según Ávila, $(2001,2009)$ la configuración espacial del proceso de periurbanización en México está dada por el flujo poblacional y el traslado de actividades productivas hacia la periferia, como en los países desarrollados, y por la estructura territorial dependiente de la evolución del modo capitalista, con las características propias del subdesarrollo mexicano:..."Las diferencias, en este sentido, radican en la intensidad de ciertos procesos y en su capacidad para explicar los cambios territoriales suscitados por la periurbanización. De esta manera, situaciones como las de segunda residencia o de movilidad cotidiana de la periferia hacia los centros urbanos (características que alimentan el proceso en la gran mayoría de los países desarrollados) si bien ocurren y están en aumento, resultan insuficientes o poco relevantes para dar cuenta del fenómeno en las sociedades latinoamericanas y, de modo particular, en la mexicana"...

Asimismo, en México no obstante a lo que se plantea existe una gran diversidad en cuanto a las expresiones territoriales en cada región. Lo cual genera una heterogeneidad proveniente de las características específicas de cada territorio en concreto, sus potencialidades, su localización así como de los actores que coexisten en los espacios trasformados..." Así, mientras en algunas zonas predominan los asentamientos marginales ubicados sobre suelos irregulares, en los cuales se carece de infraestructura y servicios públicos, en otras zonas es posible constatar la existencia de áreas residenciales apartadas de la ciudad en zonas de acceso restringido para una población de altos ingresos... es frecuente encontrar regiones donde el avance de la urbanización ocurre a lo largo de los ejes de salida de las ciudades o alrededor de obras e infraestructura recientes, conformando asentamientos difusos"... El mismo autor explica que este proceso se distingue por la heterogeneidad de sus espacios, ya que algunos han sido transformados por la dinámica urbana que induce un cambio de uso suelo, en la conservación y en la estructura productiva local y en otros se da la coexistencia de actividades agrícolas y pecuarias con actividades de tipo urbano.

Desde la década de los setenta el debate de la concepción de lo que se considera urbano y rural, surgió como una corriente revisionista en torno a la problemática de la delimitación del espacio urbano, rural y el espacio intermedio (Iglesias y Bazán, 2009; Salinas y Pérez, 2011; Vieyra y Larrazábal, 2014). Luego del análisis teórico referencial que se realizó para esta investigación, se asumen los siguientes criterios conceptuales para la definición de la zonificación que se propone:

- Urbano: De acuerdo al planteamiento de (Capel, 2002) en "la definición de lo urbano desde una perspectiva geográfica"; el criterio a tener en cuenta será la morfología como reflejo de la densidad y de un tipo de utilización del suelo de carácter no rural, la consolidación de la infraestructura y los servicios y la estructura funcional permitirán identificar posteriormente los distintos niveles de complejidad.

- Interfase Periurbana: De acuerdo a (Zuluaga, 2005) se identifica con espacios de uso del suelo heterogéneo, transformación de estructuras rurales tradicionales, transformación de las localidades en subcentros, especulación de suelo por disposición de terrenos edificables baratos, existencia de espacio de recreo e instalaciones, presencia de depósitos de residuos y problemas en el abastecimiento de servicios y equipamientos públicos en un proceso de transición.

- Rural: Según (Ávila, 2009) "El espacio rural tradicional no es más el mundo homogéneo cuya identidad giraba en torno a la actividad agrícola", por lo que en esta 
investigación se considera el entorno rural periférico de las ciudades 'espectro ruralurbano; densidad relativamente baja de habitantes y de construcciones (asentamientos dispersos y desagregados), lo que determina un predominio de los paisajes cultivados o naturales, uso económico del suelo de predominio agropecuario y crecimiento del sector terciario por lo que puede presentar multifuncionalidad del espacio, de viviendas dispersas, de conservación, o de ocio y recreación.

El acervo teórico y práctico entorno a los estudios del paisaje presenta diversos enfoques y criterios. Dado este contexto, para la aplicación de políticas públicas, gestión y manejo de la planificación urbana, el monitoreo de la situación ambiental y los gestores o decisores de estos programas, resulta imprescindible la obtención de información espacial con carácter interdisciplinario entre los aspectos físicos naturales y las formas sociales de apropiación, como plataforma para análisis ulteriores en el ámbito de factores culturales y visuales del paisaje en su evolución histórica. Si bien la presente metodología se enmarca en el análisis objetivo, teniendo como base los elementos físico-naturales del paisaje, se incorporan factores funcionales y subjetivos, propios de cada espacio, a través de la evaluación de la cobertura terrestre y el uso del suelo, que son parte del resultado de la diversidad de las relaciones socio-económicas, políticas y administrativas en la trasformación del paisaje. Por todo ello, encontramos viable nuestra propuesta a partir del enfoque geoecológico del paisaje.

\section{I.2. De la Geoecología del paisaje, las unidades espaciales y la zonificación geoecológica del paisaje}

La Geoecología del Paisaje y el enfoque geoecológico, son relativamente jóvenes, consisten en un sistema de métodos, procedimientos y técnicas de investigación, cuyos propósitos son la obtención de un conocimiento integral sobre el medio socio-natural (Huggett, 2003). La Geoecologia presta especial atención a la circulación de materia y energía entre los componentes de una unidad geográfica, la cual es operacional y se denomina complejo territorial natural, que consiste en un sistema integrador de los componentes del medio geográfico que interactúan entre sí y tienen capacidad para formar una estructura espacial de diferentes niveles de sistematización (Mateo, 2011). El concepto de geosistema y la Geografía del Paisaje fueron la influencia principal de esta ciencia, no obstante hoy en día su carácter es interdisciplinario y posee una metodología propia, siendo su principal objeto de estudio las relaciones del paisaje natural con la sociedad, como base para el entendimiento de la Región, el Territorio y el Medio Geográfico. Esta visión se centra principalmente en la localización, distribución y organización de los fenómenos geográficos y de su identificación, clasificación y cartografía (Golubev 2006, citado por Mateo, et al., 2013: 100). Por ello las categorías analíticas con las que opera la Geoecología de los Paisajes son: el paisaje; natural, antropo-natural y cultural, el espacio geográfico y el territorio. De esta manera, en el paisaje, como sistema conceptual, se produce una relación objeto-sujeto, que pasando por filtros de percepción, determinan; su objetividad, el tipo y estructuran del sistema, el análisis multidisciplinar y su realidad tangible.

Los sistemas geoecológicos o paisajes antropogénicos (urbano) han sido transformados intensamente por la actividad del hombre, en los cuales se introducen numerosos elementos 
(infraestructura de servicios, comunicaciones, familiares, etc.), a ellos se les llama elementos antropogénicos. Los elementos antropogénicos de un paisaje están directamente relacionados a los usos históricos asignados y a las coberturas que ellos determinan. La forma de organización del espacio determinada por el conjunto de tipos de usos y clases de coberturas terrestres presentes en un tiempo dado, se le denomina, estructura antropogénica de los paisajes urbanizados (Mateo, 2008). Este enfoque establece como sus unidades espaciales de análisis, al resultado de la interacción entre los paisajes naturales y su estructura antropogénica y se les conoce como unidades geoecológicas, que son delimitadas en dos niveles de interpretación, primero a partir de los componentes naturales en diferentes rangos taxonómicos y segundo la infraestructura de la actividad socioeconómica y sus funciones.

El empleo de las unidades geoecológicas para el análisis espacial del paisaje urbano, que en primera instancia son ampliamente utilizadas para el análisis integrador de sistemas naturales, se sustenta en diversas ventajas; refleja la diferenciación espacial de la interrelación entre los fenómenos que ocurren en un territorio de forma objetiva, estas unidades que por su propia definición son altamente diferenciables entre sí, se corresponden con zonas homogéneas a su interior, mediante las cuales se puede calcular, analizar, comparar y evaluar el potencial de los recursos de un territorio, asociado espacialmente y subordinado a las regularidades de su formación y diferenciación. Posibilita la obtención de resultados concretos al analizar a la sociedad y a la naturaleza, en unidades comunes que permiten la jerarquización y taxonomía del espacio urbano en diversos tamaños, complejidades y nivel de organización, por lo que pueden ser espacialmente diferenciados y cartografiados.

Un proceso de zonificación o agrupación, consiste en la separación y segregación del territorio respecto de su entorno, donde se reconocen por una parte elementos que lo diferencian, y por otra, se actúa con el fin de aislarlos para un propósito particular. Por ejemplo si nos referimos a la caracterización urbanística de un espacio, la zonificación, es la práctica de dividir una ciudad o municipio en secciones reservados para usos específicos y para determinadas coberturas terrestres, ya sean residenciales, comerciales e industriales, áreas verdes, infraestructura, etc., conforme a un análisis previo de sus aptitudes, características, cualidades e interacción con actividades antrópicas (Groppo, 1993; Jiménez, 1995). La zonificación entonces es un proceso de división o parcelamiento, ya sea regular o irregular en un área determinada, define zonas individuales que poseen características propias y un grado relativamente alto de uniformidad interna en todos o en ciertos atributos esenciales para propósitos específicos y caracteriza "zonas", lo que se realiza en función de la integración de múltiples variables que permiten la evaluación de sus aptitudes para su agrupamiento. De esta manera, la Zonificación Geoecológica es un proceso de clasificación del espacio basado en criterios naturales y sociales, se sustenta en la identificación, definición y caracterización de áreas o zonas que corresponden a los distintos usos del suelo y la cobertura terrestre en un marco geográfico determinado, tiene que ver con una multitud de variables del ambiente geográfico, físico y social y las variables determinantes son aquellas que se generan sobre la base de factores propios del paisaje local de cada zona. Estas zonas, para la presente investigación, se analizan mediante la delimitación e interpretación de la agrupación de las unidades geoecológicas, en los escenarios observados que conforman la ciudad, el entorno en la interfase del periurbano y los asentamientos rurales próximos. 


\section{I.3. La ciudad de Morelia y su entorno}

La ciudad de Morelia ocupa el $2.04 \%$ de la superficie del estado de Michoacán, se ubica entre los paralelos $19^{\circ} 27^{\prime} 06^{\prime}$ ' y $19^{\circ} 50$ ' 12 ', de latitud norte, los meridianos $101^{\circ} 01^{\prime}$ ' 43 ' ' y $101^{\circ} 30^{\prime} 32^{\prime}$ ' de longitud oeste; con una altitud entre 1500 y 3000 m. Se localiza en el municipio de Morelia que colinda con 14 municipios: al norte con Tarímbaro, Copándaro de Galeana, Chucándiro y Huaniqueo; al sur, con Acuitzio del Canje, Villa Madero y Tzitzio; al oriente, con Charo y al poniente con Coeneo, Tzintzuntzan, Lagunillas, Huiramba y Pátzcuaro. Tiene una extensión de 1,199 km² y 729,279 Hab de acuerdo al censo de población del 2010 del INEGI. Cuenta con 207 localidades registradas en el prontuario geográfico del municipio con datos del 2009, de ellas algunas destacan por ser consideradas como localidades urbanas por su número de habitantes. Al noroeste de la ciudad encontramos, la localidad de La Aldea con 6 mil 162 habitantes; al sur, la Tenencia de Morelos con 13 mil 565 habitantes que es la localidad más poblada después de la cabecera municipal; al oeste de la cabecera se ubica Capula con 5 mil 086 y al sureste la localidad de Jesús del Monte con 2 mil 142 pobladores. La ciudad de Morelia ha estructurado una relación urbano-rural con los municipios que la rodean y al interior del propio municipio con las localidades cercanas a la ciudad (INEGI, 2010). Los bienes y servicios que otorga Morelia a los municipios y localidades (que han sido invadidas o conurbadas por el proceso de urbanización) propios de la interrelación o influencia que ejerce sobre ellos son principalmente: a) Bienes: alimentos para consumo humano procesados y en fresco, alimentos procesados para consumo animal, medicamentos, bienes de consumo duradero y semiduradero, insumos para la producción y bienes de capital; b) Servicios: educativos, administrativos, de salud, bancarios, de esparcimiento, técnicos y diversos servicios profesionales. Pero hay que resaltar que esta relación no es unidireccional pues los municipios y localidades (incluidas las que todavía conservan la condición de rurales), que conforman el área de influencia, a su vez proporcionan a la ciudad alimentos frescos para consumo humano y animal principalmente (GARCÍA; CARRILLO, 2006).

La ciudad de Morelia es considerada como una ciudad media, que al igual que otros centros urbanos de México manifiesta importantes movimientos poblacionales. Ello provocó la expansión de la ciudad en un tiempo relativamente corto (HERNÁNDEZ; VIEYRA, 2010), pero durante el proceso de urbanización en la distribución del crecimiento de la ciudad ha sido desordenado y desigual y no está equilibrado con el aumento de la población precisamente. Según López y Mendoza, (2014): "Procesos de cambio de cobertura vegetal y uso del suelo en un municipio periurbano: el caso de Tarímbaro, Michoacán de Ocampo, México" en (VIEYRA; LARRAZÁBAL, 2014), a partir del año 2000 el proceso de crecimiento de la Ciudad de Morelia comienza a rebasar los límites territoriales, se ocupan hacia el sur tierras del municipio de Tarímbaro y se origina un espacio de conurbación entre estos dos municipios. De esta manera los autores describen que ha ocurrido un crecimiento de los asentamientos de tipo fraccionamientos de interés social, sobre tierras de calidad muy aptas para la agricultura.

De acuerdo a Ávila (2009), en la publicación presentada: "Especulación del suelo y deterioro socio ambiental en la Ciudad de Morelia: el caso de la desregulación de la planeación urbana (19832003)", repite la afirmación de que la ciudad de Morelia bajo las 
reformas al artículo 27 constitucional, referente al crecimiento urbano y la liberación del suelo ejidal al mercado, debido al dominio del interés privado sobre la planeación urbana, el programa de desarrollo urbano (2003-2018) acrecentaron los problemas e implicaciones ambientales a la ciudad.

\section{ENFOQUE METODOLÓGICO}

Para llegar a la zonificación de unidades geoecológicas, se elaboró un flujograma metodológico general (Fig. 1), con énfasis en la aproximación multiescalar para la comprensión del paisaje de la ciudad y su relación con el entorno. Se establecen las unidades físico-geográficas (U-FG) que representan la base físico-natural en un contexto territorial, posteriormente se analiza por medio de la tipología de la cobertura terrestre y el uso del suelo, en representación del espacio geográfico-relacional el contexto social-económico y por último se realiza la agrupación o zonificación de las unidades geoecológicas (UG) resultantes, mediante la caracterización y el análisis del comportamiento espacial en el contexto local.

Figura 1

FLUJOGRAMA DEL PROCEDIMIENTO METODOLÓGICO

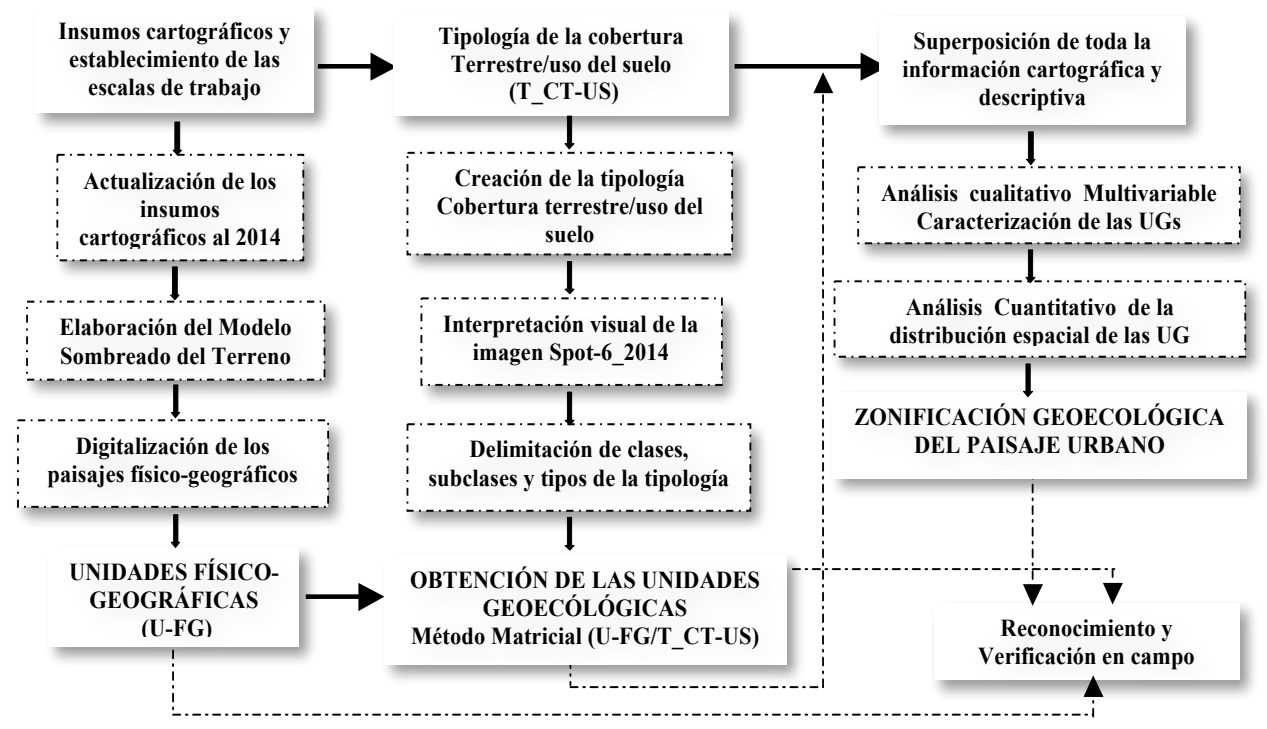

Fuente: elaboración propia con base en revisión de literatura especializada y procedimientos metodológicos.

\section{II.1. La clasificación y cartografía de las unidades físico-geográficas en el contexto territorial}

El sistema de unidades taxonómicas de las unidades físico-geográficas que se utiliza en nuestro trabajo, se basa en los criterios de clasificación del paisaje empleados por el sistema académico ruso (Vidina, 1970; adaptado por Mateo, 2008), se establecen para el área de 
estudio, dos unidades taxonómicas: la Localidad y la Comarca físico-geográfica (Paraje físico-geográfico), se tiene en cuenta la escala de representación a 1: 50000 (escala local). La identificación de los paisajes físico-geográficos se realiza por medio de cuatro etapas metodológicas (Bollo y Hernández, 2008): 1) revisión bibliográfica-cartográfica y compilación inicial de gabinete, en la cual se recopila la información analógica y cartográfica (capas temáticas) existente para el área de estudio. Las capas temáticas son estandarizadas en cuanto a proyección, escala e integridad de bases tabulares asociadas, y son actualizadas con imágenes SPOT-6 del mes de septiembre del 2014. Sobre esta base se genera el Modelo Digital de Terreno (MDT) y posteriormente se elabora el Modelo sombreado sobre el cual se establecen los límites de las unidades morfológicas del relieve como base de las localidades y comarcas físico-geográficas, 2) Se establecen las localidades físico-geográficas, a partir de la determinación de la asociación de mesoformas del relieve. Al interior de las localidades se definen las comarcas o parajes físico-geográficos, estas últimas tienen como base las partes o elementos que conforman las mesoformas del relieve, y se superponen sucesivamente los mapas de la composición litológica, las unidades de suelo, y la vegetación originaria, para obtener un mapa base o de gabinete de los paisajes físico-geográficos, 3) levantamiento de campo en el cual a partir del mapa propuesto en gabinete, con recorridos de campo se complementa, verifica y rectifica dicho mapa con la confrontación de la imagen satelital y 4) trabajo final de gabinete, con técnicas del SIG se realiza la edición final del mapa de unidades del paisajes físico-geográficos del área.

\section{II.2. Las unidades geoecológicas y su clasificación en el contexto socio-económico}

La interpretación de las unidades geoecológicas exige el desarrollo y perfeccionamiento del enfoque sistémico, el uso del modelamiento y el manejo de los sistemas geoinformativos (SIG), como herramientas de especial utilidad. El análisis diferencial entre las estructuras antropogénicas permite la comprensión de estas unidades. La clasificación de las estructuras antropogénicas en los paisajes físico-geográficos que ha ocupado una ciudad, según el uso del suelo, se relaciona con las funciones que se desarrollan sobre las cubiertas o coberturas; es la calificación de todas las actividades realizadas por el hombre sobre la cobertura terrestre de un espacio, de forma parcial o permanente, con la intención de cambiarla o mantenerla para obtener un producto o beneficio. La cobertura terrestre se refiere al aspecto morfológico y tangible del suelo, comprende todos los elementos que hacen parte del recubrimiento de la superficie terrestre, de origen natural o cultural que estén presentes (Powel, 2010; Dar, 2010; INEGI, 2012). La misma cobertura terrestre puede soportar diferentes usos y un mismo uso puede desarrollarse sobre diferentes coberturas terrestres. El diseño de la tipología de las coberturas terrestres y los usos del suelo, es fundamental para la identificación de las estructuras antropogénicas en un espacio, ello requiere una clasificación estandarizada de los espacios. La tipología de la cobertura terrestre y uso del suelo es dependiente de la escala de trabajo ya que esta define el nivel inferior que podemos establecer.

Para la cartografía de las clases y tipos de cobertura/uso, se utilizó la imagen satelital SPOT6, de 2,5 m de resolución espacial, combinación de color RGB (color natural o real). El procesamiento digital de las imágenes se realiza en varios procesos; corrección radiométrica, fusión de imágenes, segmentación e interpretación visual de las clases y 
subclases. Se confecciona un álbum de patrones de interpretación, tanto naturales como de ocupación, mediante la fotointerpretación visual y digital. Se establece el tamaño de píxel que cumple la escala de salida cartográfica, 1: 20 000, con un área mínima cartografiable de 4 x $4 \mathrm{~mm}$ o $6400 \mathrm{~m}^{2}$ (Salichtchev, 1979), se tiene en cuenta que la longitud del pixel debe ser la mitad de la longitud más pequeña que sea necesario representar. Se identifican, clases y subclases en términos de cobertura terrestre y los diferentes tipos en función del uso del suelo.

Se realiza el cruce de las unidades de paisajes físico-geográficos y la tipología de cobertura/uso de suelos, por medio de la superposición de los mapas resultantes de la cartografía de ambos temas. Se obtiene así el mapa de unidades geoecológicas y su leyenda, la cual muestra las unidades geoecológicas mediante el método matricial, en la vertical de la matriz se presentan las comarcas de paisajes físico-geográficos y en la horizontal las clases y tipos de cobertura/uso del territorio. El procedimiento culmina con la compilación cartográfica de las UGs en el área de estudio y recorridos de campo por todas las unidades geoecológicas, lo que permite realizar la descripción de variables sociales, económicas y administrativas en cada una de ellas.

\section{II.3. Zonificación de las unidades geoecológicas de la ciudad y su entorno}

La metodología utilizada para la zonificación de las unidades geoecológicas, parte del análisis multivariable de la distribución y caracterización de estas unidades. Se analiza el comportamiento espacial de las UGs identificadas en función de variables económicas, sociales, infraestructura y servicios, con el objetivo de interpretar cual es el patrón que describen en el área y la formación de grupos o zonas que presenten características homogéneas entre ellas, que puedan ser delimitadas espacialmente. Para ello, se tomaron en cuenta los criterios que se asumen para conceptualizar los espacios urbanos, periurbanos y rurales que se describieron anteriormente. Los resultados esperados de este procedimiento son obtener una delimitación espacial precisa del área a considerar como urbana, periurbana y rural en el área de aplicación.

Se realiza el análisis espacial de las unidades geoecológicas según las clases de cobertura y el uso del suelo que la conforman. Primero, se superpone la capa de las UGs formadas por las clases, Habitacional e Infraestructura para definir, por medio de los límites de dichas unidades, el límite entre la zona urbana y la zona periurbana del territorio. En el paso siguiente, se superponen las UGs con la clase de cobertura/uso, Vegetación y Áreas cultivadas. A partir de los límites de las unidades geoecológicas que conforman esta capa, se establecen los límites entre las zonas periurbana y rural del área de estudio, todo ello por medio del ambiente SIG. El límite externo de la zona rural es el límite del área de estudio. De tal manera, el análisis espacial de las UGs en el área de aplicación nos permite establecer la zonificación del territorio que ocupa la ciudad y su entorno.

Para conocer si los espacios delimitados en las zonas urbana, periurbana y rural cumplen con las características definidas para las mismas, se tienen en cuenta los criterios conceptuales establecidos para cada una de estas áreas y se revisa la descripción de las unidades geoecológicas que integran cada zona, para comprobar si cumplen con los elementos que definen a cada zona para esta investigación. 


\section{APLICACIÓN DE LA PROPUESTA METODOLÓGICA EN LA CIUDAD DE MORELIA}

\section{III.1. Las unidades físico-geográficas del paisaje en Morelia}

Como resultado del análisis se delimitaron, clasificaron y cartografiaron 4 localidades y 30 comarcas de paisajes físico-geográficos para el área de estudio, con un total de 51 polígonos. La nomenclatura que se emplea en el mapa y su leyenda, se expresa en número romano para las localidades, y se codifica con una letra minúscula, por orden alfabético, a las comarcas (Tabla 1). Una vez clasificadas las unidades físico-geográficas (FG), se compila el mapa de los paisajes físico-geográficos del área de estudio (Fig. 2).

\begin{tabular}{|c|c|}
\hline $\begin{array}{l}\stackrel{\circ}{\rho} \\
\stackrel{\rho}{\varrho}\end{array}$ & $\begin{array}{l}\text { I. a. Laderas de las montañas, formadas en Ignimbritas, dacitas y coladas de lava basálticas, } \\
\text { L a FI }\left(10^{\circ}-30^{\circ}\right) \text {, con AH, pastizal cerrado, cultivos de temporal y riego, plantaciones de } \\
\text { árboles semiabiertas, y bosque cerrado, semiabierto y abierto, sobre Leptosoles, Luvisoles } \\
\text { y Acrisoles. }\end{array}$ \\
\hline 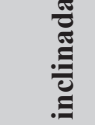 & $\begin{array}{l}\text { I. b. Laderas de las montañas, formadas en andesitas, brecha volcánica intermedia y coladas } \\
\text { de lavas basálticas, con laderas } \mathrm{L} \text { a } \mathrm{MI}\left(10^{\circ}-20^{\circ}\right) \text {, con } \mathrm{AH} \text {, cultivos de temporal y pastizal } \\
\text { cerrado, sobre Andosoles, acrisoles y Luvisoles. }\end{array}$ \\
\hline 莺 & $\begin{array}{l}\text { I. c. Cimas de las montañas, en forma de cono o cráter volcánico, formadas en basaltos, } \\
\text { con pendientes FI }\left(>30^{\circ}\right) \text { con bosque semiabierto y pastizal cerrado, sobre Luvisoles y } \\
\text { Andosoles. }\end{array}$ \\
\hline & $\begin{array}{l}\text { I. d. Laderas de las montañas, formadas por coladas de lava basáltica, LI }\left(5^{\circ}-10^{\circ}\right) \text { con } \mathrm{AH} \\
\text { y algunos cultivos de temporal, sobre Vertisoles. }\end{array}$ \\
\hline 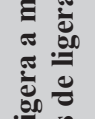 & $\begin{array}{l}\text { I. e. Laderas de las montañas, formadas por coladas de lava basáltica, } \mathrm{L} \text { a } \mathrm{MI}\left(10^{\circ}-15^{\circ}\right) \\
\text { con pastizal cerrado, matorral pastizal, cultivos de temporal, bosque abierto y } \mathrm{AH} \text {, sobre } \\
\text { Vertisoles y Luvisoles. }\end{array}$ \\
\hline 蒫 & $\begin{array}{l}\text { I. f. Lomeríos, fuertemente diseccionados }(80-100 \mathrm{~m} / \mathrm{km} 2) \text {, formados por basaltos y dacitas, } \\
\text { con laderas L a MI }\left(10^{\circ}-15^{\circ}\right) \text { y superficies cumbrales muy S a SI }\left(1^{\circ}-5^{\circ}\right) \text {, con } \mathrm{AH} \text {, pastizal } \\
\text { cerrado y cultivos de temporal y riego, sobre Leptosoles. }\end{array}$ \\
\hline & $\begin{array}{l}\text { I. g. Piedemontes, formados por colac } \\
\text { bosque abierto, cultivo de temporal, } \mathrm{m}\end{array}$ \\
\hline 总 & $\begin{array}{l}\text { I. h. Piedemontes, formados por coladas de lava basáltica, LI }\left(5^{\circ}-10^{\circ}\right) \text { con pastizal cerrado, } \\
\text { plantaciones de árboles abiertas y semiabiertas, cultivos de temporal, bordos y } \mathrm{AH} \text {, sobre } \\
\text { Vertisoles . }\end{array}$ \\
\hline சे & $\begin{array}{l}\text { I. i. Piedemontes, formados por coladas de lava basáltica, L a MI }\left(10^{\circ}-15^{\circ}\right) \text { con pastizal } \\
\text { cerrado, cultivos de temporal, matorral pastizal, bosques semiabierto y cerrado y } \mathrm{AH} \text {, sobre } \\
\text { Luvisoles. }\end{array}$ \\
\hline & $\begin{array}{l}\text { I. j. Domos y volcanes monogenéticos, formados por dacitas y riolitas, } \mathrm{L} \text { a } \mathrm{MI}\left(10^{\circ}-15^{\circ}\right) \\
\text { con pastizal cerrado, sobre leptosoles, Luvisoles, Phaeozem y Regosoles. }\end{array}$ \\
\hline 递 & $\begin{array}{l}\text { I. k. Superficie plana a suavemente ondulada }\left(<5^{\circ}\right) \text {, formada por colada de lava basáltica } \\
\text { (mal país), con AH, bosque abierto, matorral cerrado y pastizal, cultivos de temporal, sobre } \\
\text { Leptosoles. }\end{array}$ \\
\hline
\end{tabular}




\begin{tabular}{|c|c|}
\hline$\stackrel{\circ}{\circ}$ & $\begin{array}{l}\text { II. a. Laderas de las montañas, formadas en andesitas, mediana a fuertemente inclinadas } \\
\left(20^{\circ}-30^{\circ}\right) \text { con cimas en forma de conos, sobre Acrisol y Luvisoles. }\end{array}$ \\
\hline$\stackrel{\substack{1 \\
ٍ}}{\stackrel{1}{0}}$ & $\begin{array}{l}\text { II. b. Laderas de las montañas, formadas en Ignimbritas, L a MI }\left(10^{\circ}-20^{\circ}\right) \text { con pastizal } \\
\text { cerrado, cultivo de riego y temporal, plantaciones de árboles cerradas, bosque cerrado, } \\
\text { semiabierto y abierto, sobre Acrisol, Andosoles, Leptosoles y Luvisoles. }\end{array}$ \\
\hline 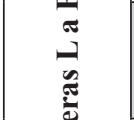 & $\begin{array}{l}\text { II. c. Laderas de las montañas, formadas en basaltos y dacitas, } \mathrm{M} \text { a FI }\left(20^{\circ}-30^{\circ}\right) \text { con pastizal } \\
\text { cerrado, cultivo de riego y temporal, plantaciones de árboles cerradas, bosque cerrado, } \\
\text { semiabierto y abierto, sobre Acrisol, Andosoles, Leptosoles y Luvisoles. }\end{array}$ \\
\hline 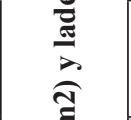 & $\begin{array}{l}\text { II. d. Piedemontes, formados por Ignimbritas, } \mathrm{S} \text { a LI }\left(3^{\circ}-10^{\circ}\right) \text { con } \mathrm{AH} \text {, matorral pastizal, } \\
\text { pastizal cerrado, cultivos de temporal, plantaciones de árboles cerradas y bosque abierto, } \\
\text { sobre luvisoles. }\end{array}$ \\
\hline 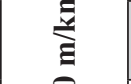 & $\begin{array}{l}\text { II. e. Superficie cumbral, formada en Ignimbritas, con laderas muy } \mathrm{S} \text { a } \mathrm{LI}\left(1^{\circ}-10^{\circ}\right) \text { con } \mathrm{AH} \text {, } \\
\text { pastizal cerrado y cultivos de temporal y de riego, sobre luvisoles. }\end{array}$ \\
\hline 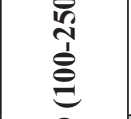 & $\begin{array}{l}\text { II. f. Cañones fluviales, formados en dacitas y basaltos, profundos (DV }>40-100 \mathrm{~ms} \text { ), } \\
\text { con corrientes permanentes y vegetación de bosque semiabierto, matorral pastizal, pastizal } \\
\text { cerrado, sobre leptosoles. }\end{array}$ \\
\hline : & $\begin{array}{l}\text { II. g. Conos volcánicos, formados por depósitos de caída y brecha volcánica, L a MI }\left(10^{\circ} \text { - }\right. \\
\left.20^{\circ}\right) \text {, con pastizal cerrado, cultivo de riego y temporal, plantaciones de árboles cerradas, } \\
\text { bosque cerrado, semiabierto y abierto, sobre Acrisol, Andosoles, Leptosoles y Luvisoles. }\end{array}$ \\
\hline$\overline{\bar{\theta}}$ & $\begin{array}{l}\text { II. h. Superficie cumbral, muy S a LI }\left(1^{\circ}-10^{\circ}\right) \text {, con laderas ligera a medianamente inclinadas } \\
\left(10^{\circ}-20^{\circ}\right) \text {, con AH y bosque cerrado, sobre Luvisoles y Phaeozems. }\end{array}$ \\
\hline$\dot{\Xi}$ & $\begin{array}{l}\text { II. i. Macro-pendiente de las montañas, escarpada }\left(>30^{\circ}\right) \text {, tectónica, en depósitos de caída, } \\
\text { con AH y bosque cerrado sobre Luvisoles. }\end{array}$ \\
\hline Еี & $\begin{array}{l}\text { III. a. Laderas de las montañas, formadas en Ignimbritas, } \mathrm{L} \text { a MI }\left(15^{\circ}-20^{\circ}\right) \text {, con superficies } \\
\text { cumbrales muy S a SI }\left(1^{\circ}-5^{\circ}\right) \text {, con matorral, pastizal y AH, sobre Leptosoles. }\end{array}$ \\
\hline 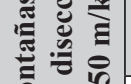 & $\begin{array}{l}\text { III. b. Laderas de las montañas, formadas en basaltos y andesitas, L a FI }\left(15^{\circ}-30^{\circ}\right) \text {, en partes } \\
\text { escarpadas. }\end{array}$ \\
\hline & III. c. Piedemontes, formados por depósitos de caída, con pendientes SI $\left(3^{\circ}-5^{\circ}\right)$. \\
\hline 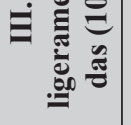 & $\begin{array}{l}\text { III. d. Lomeríos ligera a medianamente diseccionados }(40-100 \mathrm{~m} / \mathrm{km} 2) \text { formados en } \\
\text { basaltos, dacitas, y depósitos de caída, con laderas desde muy S a FI }\left(3^{\circ}-30^{\circ}\right) \text {, en partes } \\
\text { escarpadas, con } \mathrm{AH} \text {, pastizal cerrado y cultivos de temporal, sobre Phaeozem. }\end{array}$ \\
\hline $\overrightarrow{\tilde{E}}$ & $\begin{array}{l}\text { IV. a. Fondo de los valles fluviales, amplios, en depósitos superficiales fluviales y sobre } \\
\text { lavas volcánicas basálticas, planos a muy SI }\left(1^{\circ}-3^{\circ}\right) \text {, con AH, cultivos de temporal, matorral } \\
\text { cerrado y matorral-pastizal, sobre Vertisoles, Phaeozem. }\end{array}$ \\
\hline 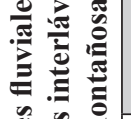 & $\begin{array}{l}\text { IV. b. Terrazas fluviales erosivas (restos) }(15-20 \mathrm{~m} / \mathrm{km} 2) \text {, formadas en Ignimbritas, planas } \\
\text { a muy SI }\left(1^{\circ}-3^{\circ}\right) \text {, con } \mathrm{AH} \text {, cultivos de temporal, matorral cerrado y matorral-pastizal, sobre } \\
\text { Vertisoles, Phaeozem. }\end{array}$ \\
\hline & IV. c. Valles estrechos. \\
\hline >. & IV. d. Depresiones interlávicas. \\
\hline Z & $\begin{array}{l}\text { IV. e. Depresión intermontañosa, en depósitos de caída y lacustres, con fondo muy } \mathrm{S} \text { a } \\
\text { LI }\left(1^{\circ}-10^{\circ}\right) \text { y laderas desde muy } \mathrm{S} \text { a FI }\left(3^{\circ}-30^{\circ}\right) \text {, con } \mathrm{AH} \text {, cultivos de temporal, matorral } \\
\text { cerrado y matorral-pastizal, sobre Vertisoles. }\end{array}$ \\
\hline PRESA & PRESA \\
\hline
\end{tabular}

Leyenda: S-Suave, L-Ligera, M-Mediana, F-Fuertemente, I-Inclinada y AH-Asentamiento Humano.

Fuente: Elaboración propia con base en la descripción de la leyenda de las unidades del paisaje. 


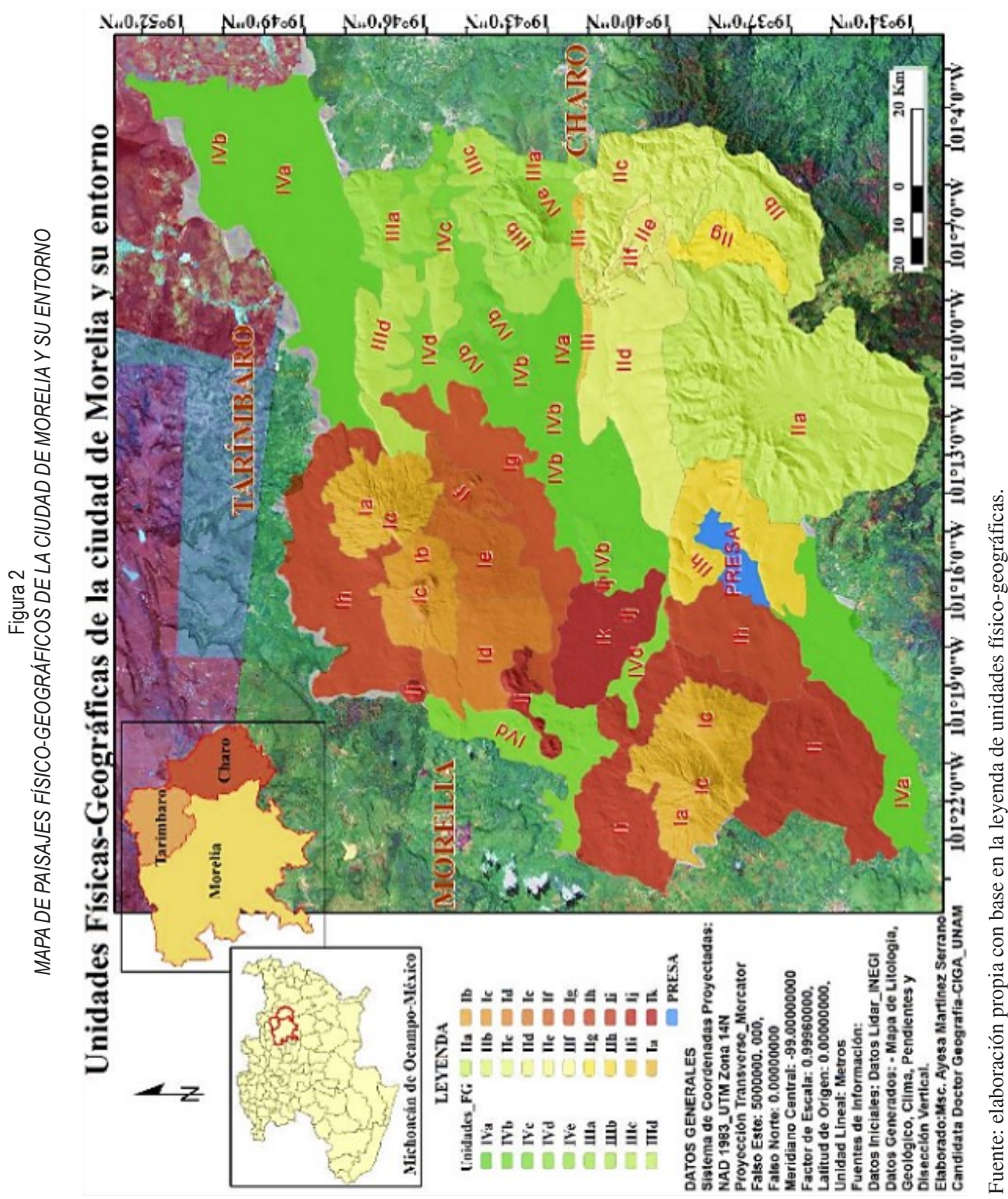




\section{III.2. La ciudad de Morelia, su entorno y las unidades geoecológicas}

Establecida la tipología se procedió a realizar la digitalización de las clases y los tipos de cada cobertura y usos del suelo, mediante la interpretación visual y la verificación en campo. Como resultado se digitalizaron 783 polígonos que se agrupan en las 6 clases y 34 usos del suelo, establecidos en la tipología, respectivamente (Tabla 2).

Tabla 2

LEYENDA DE LA TIPOLOGÍA DE LA COBERTURA TERRESTRE Y EL USO DEL SUELO

\begin{tabular}{|c|c|c|}
\hline CLASES & \multicolumn{2}{|l|}{ SUBCLASES / Tipos } \\
\hline \multirow{5}{*}{ I-Habitacional } & A- Habitacional Continuo Denso & F- Casco Histórico \\
\hline & B- Habitacional Continuo Medio Denso & G- Viviendas H Discontinuas en Bloques \\
\hline & C- Habitacional Discontinuo de Baja Densidad & H- Viviendas Discontinuas Dispersas \\
\hline & D- Habitacional Discontinuo Aislado & I- Viviendas Aisladas \\
\hline & E- Habitacional Edificaciones & $\begin{array}{l}\text { J- Viviendas Irregulares de materiales } \\
\text { temporales de tipo irregular }\end{array}$ \\
\hline \multirow{5}{*}{$\begin{array}{l}\text { II-Infraestructura } \\
\text { Equipamiento }\end{array}$} & K- Instalaciones Recreativas & O- Instalaciones Almacenamiento \\
\hline & L- Instalaciones Deportivas & P- Instalaciones Varias \\
\hline & M- Instalaciones Comerciales & Q- Instalaciones Productivas \\
\hline & N- Instalaciones Educativas & R- Instalaciones Panteón \\
\hline & $\tilde{N}$ - Instalaciones Industriales & $\begin{array}{l}\text { S- Instalaciones de Aserraderos y } \\
\text { ladrilleras }\end{array}$ \\
\hline \multirow{5}{*}{ III- Área verde } & \multicolumn{2}{|l|}{ T- Vegetación Densa } \\
\hline & \multicolumn{2}{|l|}{ U- Vegetación Baja Densidad } \\
\hline & \multicolumn{2}{|l|}{ V- Vegetación árboles aislados y zonas de pastos } \\
\hline & \multicolumn{2}{|l|}{ W- Matorral baja densidad } \\
\hline & \multicolumn{2}{|l|}{ X- Pastizal } \\
\hline \multirow{3}{*}{ IV-Área Cultivada } & \multicolumn{2}{|l|}{ Y- Cultivos compactos densos } \\
\hline & \multicolumn{2}{|l|}{ Z- Cultivos Dispersos } \\
\hline & \multicolumn{2}{|l|}{ AA- Cultivos Dispersos con matorrales o pastizales } \\
\hline \multirow{4}{*}{$\begin{array}{l}\text { V- Suelo } \\
\text { Degradado }\end{array}$} & \multicolumn{2}{|l|}{ BB- Suelo desnudo (baldíos) } \\
\hline & \multicolumn{2}{|l|}{ CC-Suelo desnudo y matorrales aislados } \\
\hline & \multicolumn{2}{|l|}{ DD- Banco de Materiales } \\
\hline & \multicolumn{2}{|c|}{ EE- Depósitos de residuos (compilación de desechos industriales o domésticos) } \\
\hline \multirow{2}{*}{$\begin{array}{l}\text { VI- Cobertura } \\
\text { Hídrica }\end{array}$} & \multicolumn{2}{|c|}{ FF- Cuerpos de agua } \\
\hline & \multicolumn{2}{|l|}{ GG- Cañada GG } \\
\hline
\end{tabular}

Fuente: elaboración propia con base en la literatura especializada y la interpretación de la imagen Spot6.

Posteriormente mediante el método matricial y como resultado del cruce de información de las unidades físico-geográficas y los polígonos según la tipología del uso y la cobertura, se obtuvieron las unidades geoecológicas del territorio (Tabla 3). Se documentaron 247 unidades geoecológicas para el territorio, que agrupan 783 polígonos y se describieron las características de cada unidad con información obtenida mediante trabajo de campo y referencias fotográficas. El procedimiento culminó con la compilación cartográfica de las Unidades Geoecológicas del área de estudio (Fig. 3) y su descripción a partir de los recorridos de campo realizados, así como la creación de una bitácora fotográfica. 


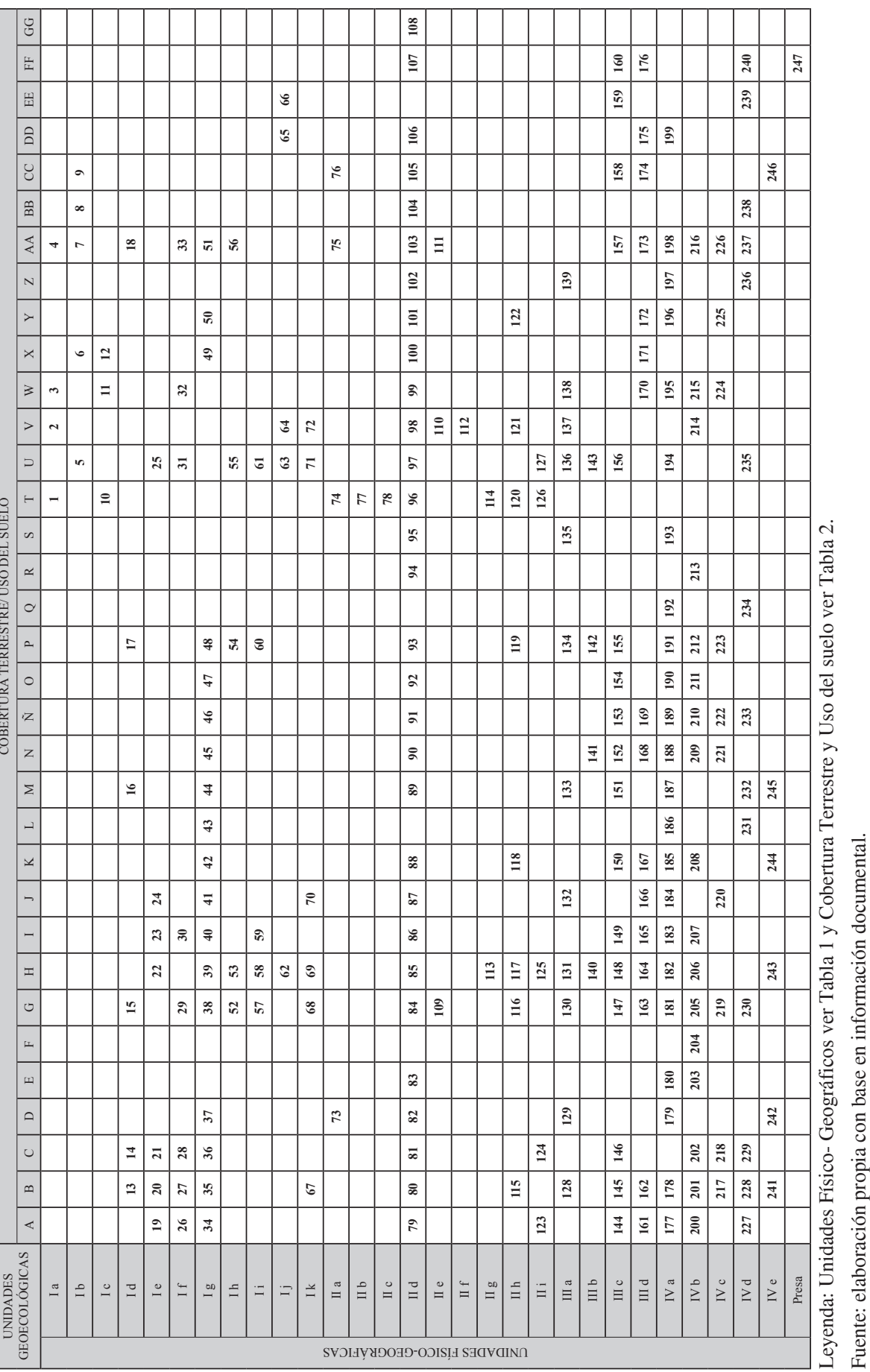




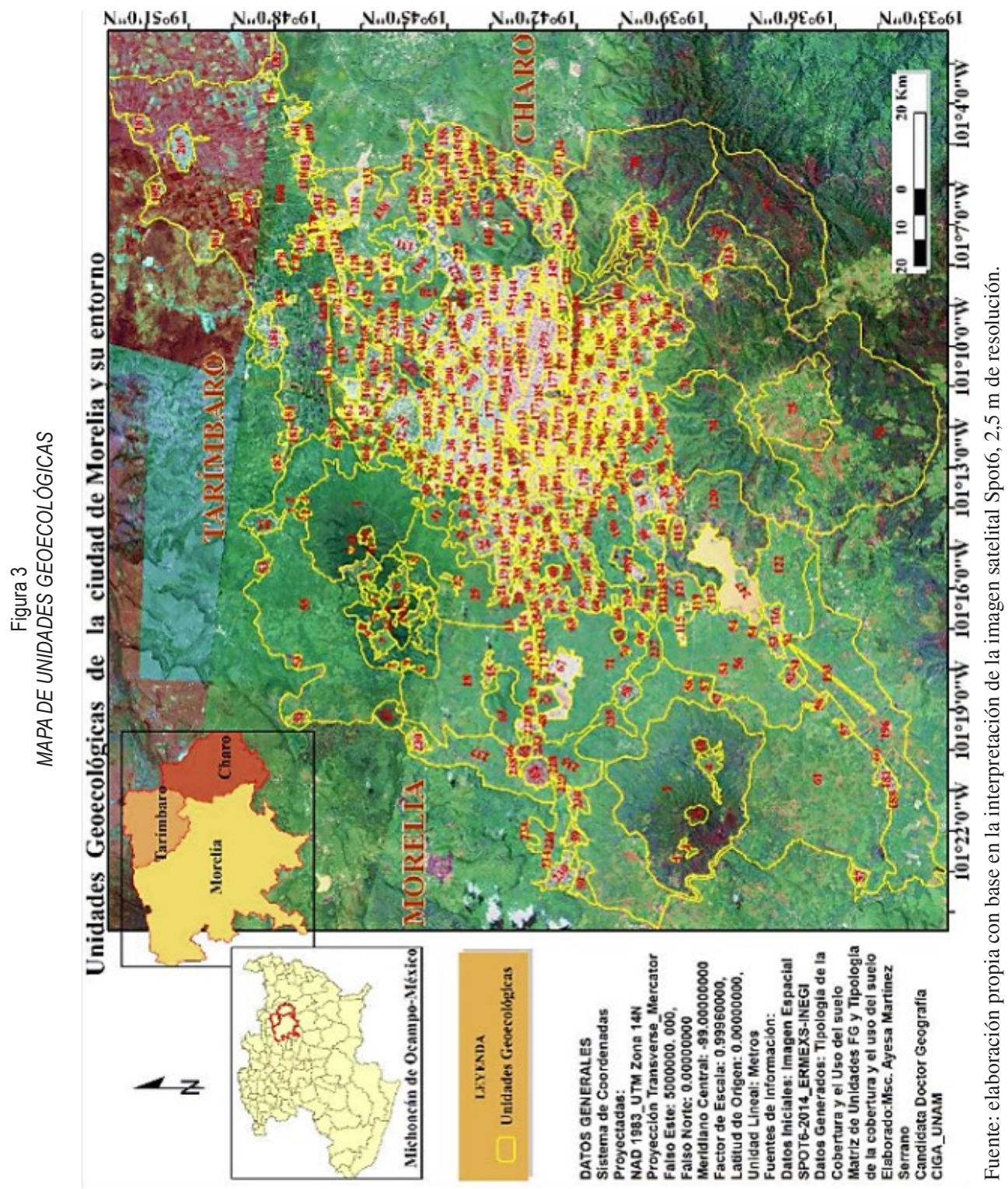




\section{III.3. Zonificación geoecológica del paisaje urbano y en proceso de urbanización}

Zonificación geoecológica del paisaje en áreas urbanas: Las unidades geoecológicas urbanas constituyen 410 polígonos del total obtenido para el área (783), y una superficie de $94,98 \mathrm{Km}^{2}$. Para su descripción se tiene en cuenta la caracterización general por paisaje físico-geográfico y tipología de cobertura terrestre y uso del suelo que representan; ocupan parte de las 4 localidades, representadas por 15 comarcas físico-geográficas del territorio: I d, I e, I f, I g, II a, II d, II i, III a, III b, III c, III d, IV a, IV b, IV c y IV d. Esto representa un total de 408 polígonos, con el predominio de las unidades físico- geográficas; IV a, I g, II d y IV b, por lo que la zona urbana se caracteriza principalmente por ocupar el fondo del valle fluvial del Río Grande de Morelia, amplio, con depósitos superficiales fluviales y lavas volcánicas basálticas e ignimbritas, pendientes planas a muy suavemente inclinadas $\left(1^{\circ}-3^{\circ}\right)$, con restos de terrazas fluviales erosivas sobre suelos Vertisoles y Phaeozem. Ocupa también un paisaje de piedemontes, formados por ignimbritas o por coladas de lava basáltica, muy suave a ligeramente inclinados $\left(3^{\circ}-10^{\circ}\right)$ con suelos Leptosoles. En particular, la parte central que caracteriza las unidades geoecológicas urbanas está ocupada por el tipo de uso denominado "Casco histórico de la ciudad de Morelia" (F), los tipos de uso de la cobertura Habitacional: A, B, C, D, E y los tipos de usos de la cobertura Infraestructura - Equipamiento: K, L, M, N, $\tilde{N}, \mathrm{O}, \mathrm{P}, \mathrm{Q}, \mathrm{R}$. Se identifican también entre estas unidades; sub-centros urbanos los que se caracterizan por desarrollar servicios especializados, típicos de centros urbanos que concentran centros comerciales y servicios, y además, por la presencia de instituciones de gobierno, de administración y los servicios públicos. Existe una red estructurada de servicios como: agua entubada, electricidad, alcantarillados, viales y obras hidrotécnicas que atraviesan la ciudad. Las UGs urbanas con área totalmente urbanizada de este espacio ocupan aproximadamente el $90 \%$, mientras que el $10 \%$ son espacios de cobertura vegetal referida a áreas verdes de jardines, espacios baldíos con matorral-pastizal, pastizal cerrado y algunos bosques cultivados cerrados y abiertos (Fig. 4).

Figura 4

ESCENARIO DE LA ZONIFICACIÓN GEOECOLÓGICA URBANA

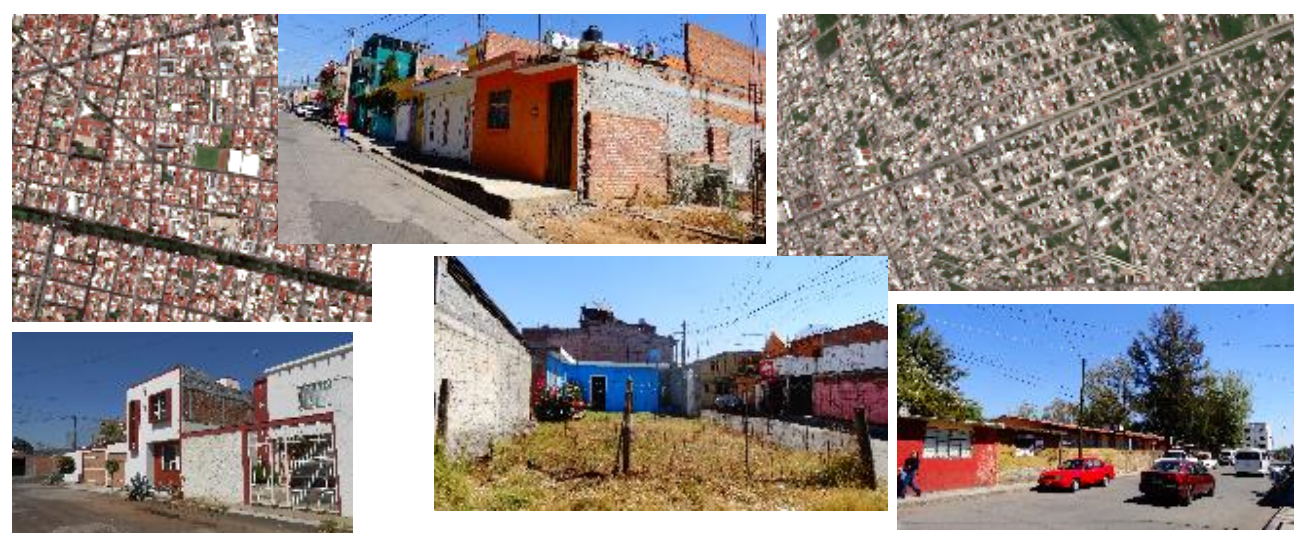

Fuente: elaboración propia con información compilada en campo y gabinete. 
Zonificación geoecológica del paisaje en áreas periurbanas: Las unidades geoecológicas periurbanas constituyen 243 polígonos del total obtenido para el área (783), y una superficie de $140,78 \mathrm{Km}^{2}$. Para su descripción se tiene en cuenta la caracterización general por paisaje físico-geográfico y tipología de cobertura terrestre y uso del suelo que representan; ocupan otra parte de las 4 localidades, representadas por 23 comarcas físico-geográficas del territorio: I a, Id, I e, I f, I g, I h, I j, I k, II a, II c, II d, II f, II h, II i, III a, III b, III c, III d, IV a, IV b, IV c, IV d y IV e, en total agrupan 242 polígonos; de los cuales predominan las comarcas: II d, IV a, III d, I g, III a y III c, por lo que las unidades geoecológicas en la zona periurbana ocupan los piedemontes, con rocas de tipo ignimbritas, coladas de lava basáltica depósitos de caída, suave a ligeramente inclinados $\left(3^{\circ}-10^{\circ}\right)$; las laderas de montañas de ignimbritas, ligera a medianamente inclinadas $\left(15^{\circ}-20^{\circ}\right)$, las superficies cumbrales muy suave a suavemente inclinadas $\left(1^{\circ}-5^{\circ}\right)$; los lomeríos ligera a medianamente diseccionados $\left(40-100 \mathrm{~m} / \mathrm{km}^{2}\right)$ formados en basaltos, dacitas, y depósitos de caída, con laderas desde muy suave a fuertemente inclinadas $\left(3^{\circ}-30^{\circ}\right)$, en partes escarpadas y el fondo de valles fluviales amplios, con depósitos fluviales superficiales o sobre lavas volcánicas basálticas, planos a muy suavemente inclinados $\left(1^{\circ}-3^{\circ}\right)$. La diversidad del paisaje físico-geográfico, es incompatible con el uso urbano, pero se encuentra parcialmente urbanizado y con tendencia a la expansión. Las UGs identificadas se caracterizan por los tipos de uso de la clase Habitacional: B, D, G, H e I, Infraestructura - Equipamiento: K, L, M, N, Ñ, P y S, además Cultivos: AA y Suelos desnudos: CC. Estas se identifican por subespacios de uso predominante en comercios, servicios y equipamiento a nivel urbano, se reconocen elementos de la estructura urbana en forma de corredores sobre las vialidades, espacios que conforman asentamientos urbanos, predominantemente habitacionales, mezcladas con servicios e industria y de equipamiento de nivel básico de tipo baja intensidad. El servicio de agua entubada se proporciona mediante la red de Organismo Operador de Agua Potable Alcantarillado y Saneamiento de Morelia (OOAPAS) principalmente y mediante pipas y pozos que la población local maneja o contrata, el sistema de alcantarillado es discontinuo (Fig. 5).

\section{Figura 5}

ESCENARIO DE LA ZONIFICACIÓN GEOECOLÓGICA PERIURBANA.

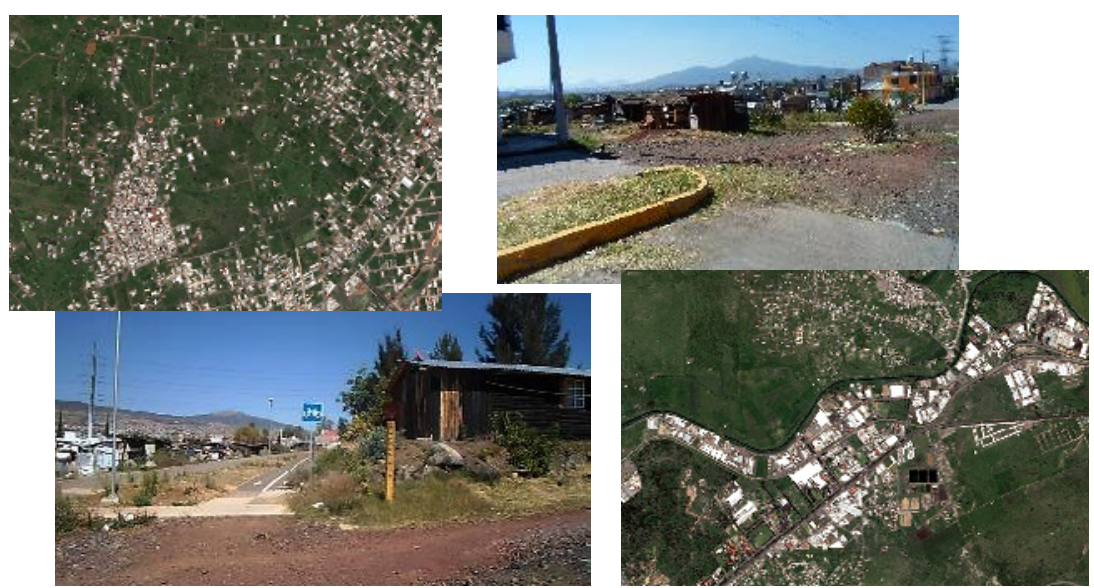

Fuente: elaboración propia con información compilada en campo y gabinete. 
El servicio de energía está a cargo de la CFE, existen instalaciones ilegales. La infraestructura vial es de segundo y tercer orden, de asfalto y terracería. Las viviendas son principalmente de tipología de casas independientes; de 1 y 2 pisos y hasta 3 pisos, estucadas y pintadas y sin estucar o pintar, con patio, jardines, unifamiliar, se aprecia que la población local posee pocos recursos económicos por la calidad de las construcciones de las viviendas en algunos espacios. Existen además viviendas con tipología de materiales temporales, en muy malas condiciones y a excepción de algunas que mejoran la construcción, pero la mayoría no cumple las reglas básicas de construcción. Se observa cobertura vegetal en un $20 \%$ del área referida a espacios baldíos, presencia de matorral pastizal, pastizal cerrado, cultivos de temporal, plantaciones de árboles cerradas y bosque abierto.

Zonificación geoecológica del paisaje en áreas rurales (Fig. 6): Las unidades geoecológicas rurales constituyen 140 polígonos del total obtenido para el área (783), y una superficie de $570.17 \mathrm{Km}^{2}$. Para su descripción se tiene en cuenta la caracterización general por paisaje físico-geográfico y tipología de cobertura terrestre y uso del suelo que representan; ocupan una parte de las 4 localidades representadas en 29 comarcas físico-geográficas del territorio: I a, I b, I c, I d, I e, I f, I g, I h, I j, I k, II a, II b, II c, II d, II e, II f, II g, II h, II i, III a, III c, III d, IV a, IV b, IV c, IV d, IV e y la presa Cointzio, representados por 131 polígonos en total, de los cuales predominan las comarcas; IV a, IV d, I b, I h, II d y I a, por lo que el paisaje rural ocupa paisajes físico-geográficos del fondo de valles fluviales, amplios, con depósitos superficiales fluviales y sobre lavas volcánicas basálticas, planos a muy suavemente inclinados $\left(1^{\circ}-3^{\circ}\right)$; paisajes en depresiones interlávicas; en laderas de montañas, con andesitas, brecha volcánica intermedia y coladas de lavas basálticas, ligera a medianamente inclinadas $\left(10^{\circ}-20^{\circ}\right)$; en laderas de montañas formadas en ignimbritas, dacitas y coladas de lava basálticas, ligera a fuertemente inclinadas $\left(10^{\circ}-30^{\circ}\right)$ y en piedemontes, con coladas de lava basáltica, ligeramente inclinados $\left(5^{\circ}-10^{\circ}\right)$. Las unidades geoecológicas que caracterizan la zona rural definida se encuentran en áreas que circundan la periferia, se caracterizan por la baja densidad de población y de construcción. Las UGs rurales están constituidas principalmente por los tipos de usos: G, H, T, U y AA; solamente se encuentran desarrollos suburbanos tipo

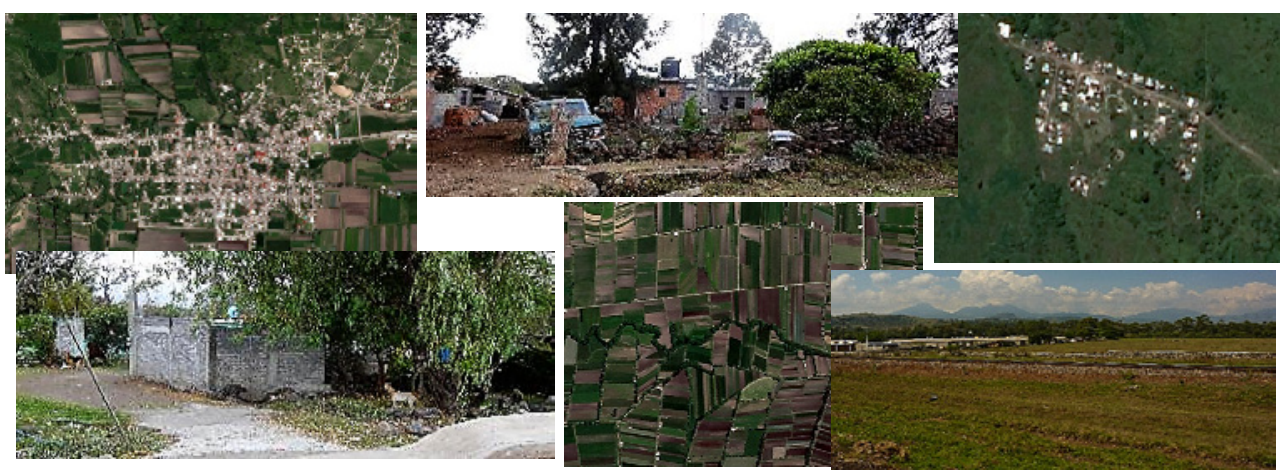

Fuente: elaboración propia con información compilada en campo y gabinete. 


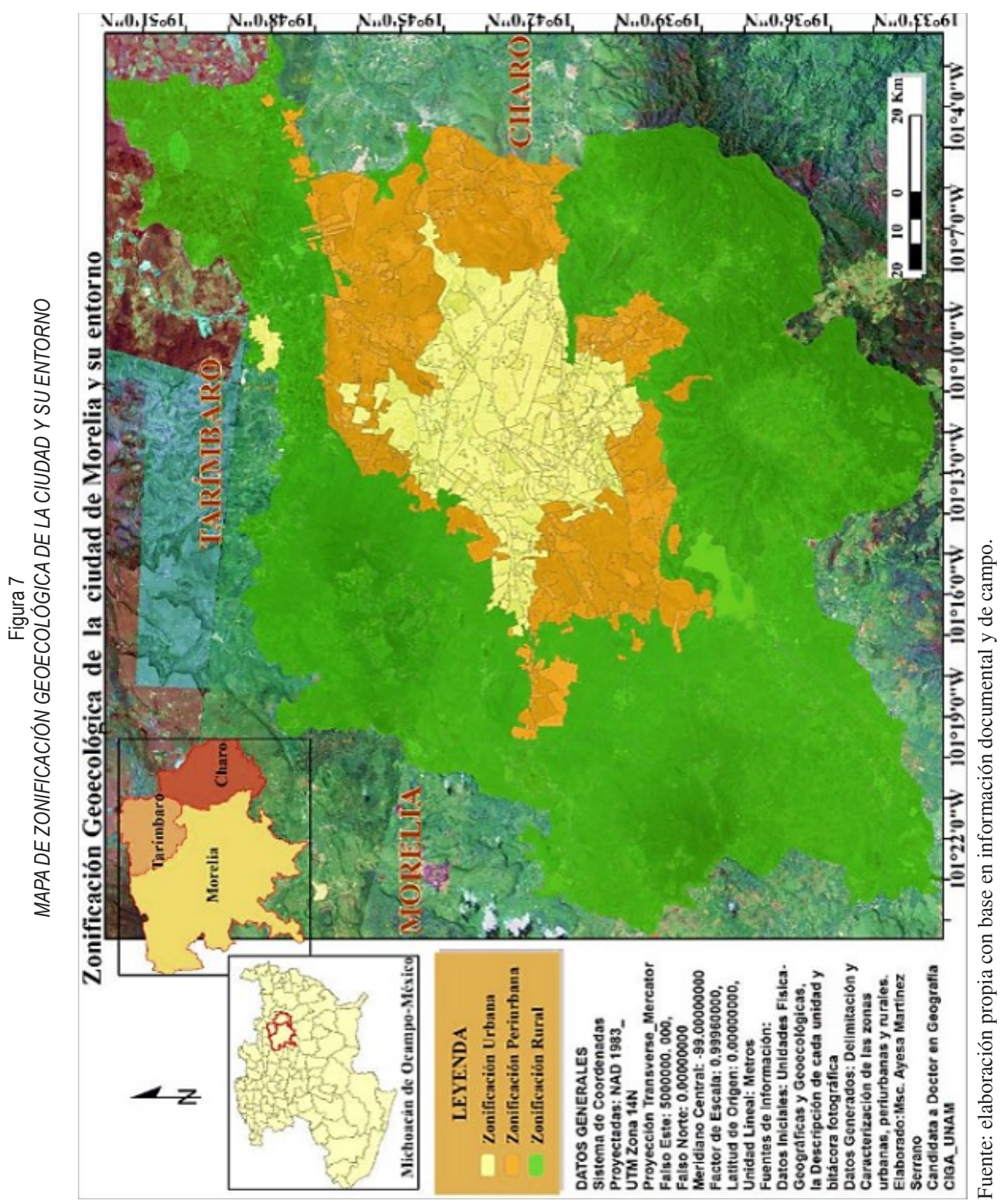


campestre y rústico, tipo granja, concentra predominantemente viviendas unifamiliares con una densidad mínima, que por sus características de funcionamiento alberga el uso habitacional, compuesto con un mínimo de equipamiento y servicios básicos preferentemente de baja intensidad (barrios). Contiene el Corredor Metropolitano, es decir, aquellos enlaces regionales en donde se establecerán funciones de equipamiento y servicios a nivel metropolitano y usos que por su modalidad e intensidad son incompatibles con el área urbana, encontramos espacios rústicos dedicados a la agricultura de riego, de temporal, actividades pecuarias y algunas áreas de protección natural. Se observa cobertura vegetal referida a matorrales, algunos árboles aislados de baja estatura y poca densidad y pasto.

\section{CONCLUSIONES}

El estudio de la temática urbano-ambiental se lleva a cabo por diferentes especialistas que en ocasiones colaboran para crear grupos interdisciplinarios y así intentar dar solución a las problemáticas observadas en las ciudades. Para poder desarrollar estas investigaciones, surgen problemas muy específicos, entre los que se encuentran definir las unidades de análisis consideradas en cada disciplina, que por lo general difieren entre ellas. Las unidades geoecológicas delimitadas permiten identificar el basamento físico - geográfico de los paisajes sobre los cuales se asentó y creció la ciudad y el resultado de la interacción paisaje natural - ocupación de la actividad humana. Desde esta perspectiva, resulta recomendable emplear estas unidades espaciales, en los análisis de la problemática social, económica y ambiental debido a que las mismas representan sistemas funcionales de la interacción entre la naturaleza y la sociedad que manifiestan la apropiación histórica del territorio y sus consecuencias.

Este método que toma en consideración aspectos físico-geográficos, las coberturas terrestres y los usos del suelo de la ciudad y su entorno de influencia, brinda una perspectiva diferente a los métodos tradicionales para la diferenciación de los espacios asociados a las ciudades bajo el proceso de urbanización. En particular, la zonificación obtenida facilita el diagnóstico de manera diferenciada para los diferentes espacios que conforman la ciudad y su entorno. Esta aplicación permitió analizar la ciudad a nivel local, delimitando unidades espaciales del territorio a detalle con criterios biofísicos, a nivel de atributos específicos del paisaje con criterios socioeconómicos, y se tuvo en cuenta el área de influencia de centros poblados o comunidades con la ciudad, genera información sobre las potencialidades y limitaciones del territorio que sirven de base para la elaboración, aprobación y promoción de proyectos de desarrollo, planes de manejo en áreas y temas específicos en el ámbito local. De igual manera, contribuye al ordenamiento y/o acondicionamiento territorial, así como al plan de desarrollo urbano. No obstante, se recomienda para aplicaciones futuras incorporar criterios de percepción del espacio por los habitantes, y así integrar métodos de la Geografía de la Percepción donde se tienen en cuenta elementos del paisaje cultural, en donde se desarrollan las formas de vivir y relacionarse, de apropiarse y de aprehender los espacios del entorno.

\section{AGRADECIMIENTOS}

Los autores agradecen los apoyos del Posgrado en Geografía de la Universidad Nacional Autónoma de México, del PAEP de la UNAM y de las Becas de CONACYT. Además, desea- 
mos reconocer al ERMEXS por el apoyo en la disponibilidad de la imagen espacial de alta resolución Spot-6 del 2013 que permitieron la realización de esta investigación, que es parte de una tesis de Doctorado en Ciencias Geográficas de la Universidad Nacional Autónoma de México.

\section{REFERENCIAS BIBLIOGRÁFICAS}

ARCIA, R. M. (1994): Geografía del medio ambiente, UAEM, Toluca, México.

ÁVILA, H. (2009): "Periurbanización y espacios rurales en la periferia de las ciudades", en Estudios Agrarios, Revista de la Procuraduría Agraria del Gobierno Federal Mexicano. Disponible en http://www.pa.gob.mx/publica/rev_41/ANALISIS/7\%20HECTOR\%20 AVILA.pdf

ÁVILA, H. (2001): "Ideas y planteamientos teóricos sobre los territorios periurbano. Las relaciones campo-ciudad en algunos países de Europa y América”, Investigaciones Geográficas. Boletín del Instituto de Geografía, UNAM, no 45, pp. 108-127.

BADIA, A., ESTANY, G., OTERO, I. y BOADA, M. (2010): "Estudio del crecimiento urbano disperso y los cambios en el paisaje de Matadepera (Región Metropolitana de Barcelona)”, Boletín de la Asociación de Geógrafos Españoles, nº 54, pp. 301-322.

BINIMELIS, J. (2000): "Sociedad postindustrial y dialéctica campo-ciudad. Aportaciones al debate a modo de estado de la cuestión”, Lurralde: Investigación y Espacio, $\mathrm{n}^{\mathrm{o}}$ 23, pp. 93-113.

BOLLO, M. y HERNÁNDEZ, J. R. (2008): "Paisajes físico-geográficos del noroeste del estado de Chiapas, México", Revista Investigaciones Geográficas, Boletín del Instituto de Geografía, UNAM, nº 66, pp. 7-24.

BORRUSO, G. (2003): "Network Density and the Delimitation of Urban Areas", Transactions in GIS, Vol. 7 (2), pp. 177-191.

BUREL, F. y BAUDRY, J. (2003): Landscape ecology: concepts, methods and applications, Enfield, New Hampshire, Science Publishers.

DE BOLÓS, M. (1992): Manual de la ciencia del paisaje. Teoría, métodos y aplicaciones, Barcelona, España.

CASTILLO, M.E. (2006): "Delimitación de unidades ambientales biofísicas en el volcán La Malinche con base en el análisis de unidades morfogenéticas", Tesis de Maestría, Facultad de Filosofía y Letras, UNAM, México.

CAPEL, H. (2002) La morfología de las ciudades, Vol. I: Sociedad, cultura y paisaje urbano, Editorial: Ediciones del Serbal, pp. 544-656.

CAPEL, H. (1975) "La definición de lo urbano", Estudios Geográficos, n 138-139, pp. 265-301.

DAR, R. (2010): “Characterizing Urban Land-Cover Change in Rondónia, Brazil: 1985 to 2000", Journal of Latin American Geography, vol. 9 (3), pp. 183-211.

GARCÍA, J.O. y CARRILLO, E., (2006): Relación Urbano Rural y Medio Ambiente en la Región Centro de Michoacán, México. Tercer encuentro internacional sobre Desarrollo sostenible y población, realizado del 6 al 24 de julio.

GARCÍA, A. y Muñoz J. (2002): El paisaje en el ámbito de la Geografía, Colec. Temas Selectos de Geografía de México (III.2), Instituto de Geografía, UNAM, México. 
GROPPO, P. (1993) El análisis comparativo de los sistemas de producción, Dirección de Recursos Humanos, Instituciones y Reforma Agraria, FAO. 27 pp.

HERNÁNDEZ, J. A. y VIEYRA, A. (2010): "Riesgo por inundaciones en asentamientos precarios del periurbano. Morelia, una ciudad media mexicana ¿El desastre nace o se hace?”, Revista de Geografía Norte Grande, n 47, pp. 45-62.

HERNÁNDEZ, J.Á., MARTÍNEZ, B., MÉNDEZ, J.A., PÉREZ, R.; RAMÍREZ, J. y NAVARRO, H. (2009): "Rurales y periurbanos: una aproximación al proceso de conformación de la periferia poblana”, Papeles de Población, vol. 15, n 61, Universidad Autónoma del Estado de México, pp. 275-295.

HUGGETT, R. (2003): Geoecology: an evolutionary approach. New York, Estados Unidos de América.

INEGI-Instituto Nacional de Estadística Geografía e Informática (2012): Guía para la interpretación de cartografía: Uso del suelo y vegetación, escala 1:250 000, serie IV. México.

IGLESIAS, G. y BAZÁN, A. (2009): "El periurbano marplatense. una propuesta de delimitación”, ponencia presentada en el X Seminario de RedMuni: "Nuevo rol del Estado, nuevo rol de los Municipios", Argentina, La Red Nacional de Centros Académicos dedicados al Estudio de la Gestión en Gobiernos Locales, 13 y 14 de agosto.

JIMÉNEZ, W. (1995): Zonificación agroecológica de la región de Acosta. Avances de Investigación, 13. Edit. CEDECO. San José-Costa Rica.

LÓPEZ, E., RANGEL, V. y MENDOZA, M. (2014): Procesos de cambio de cobertura vegetal y uso del suelo en un municipio periurbano: el caso de Tarímbaro, Michoacán de Ocampo, México, cap. en: Urbanización, Sociedad y Ambiente, experiencias en ciudades medias", Editorial Morelia Valladolid S. de R. L. de C. V., en Ciudad de Morelia, México, 294 pp., 151-196 pp.

LÓPEZ, J. y VILLERS, L. (1995): “Delineating boundaries of environmental units for land management using a geomorphological approach and GIS: a study in Baja California, Mexico", Remote Sensing of Environment, vol. 53 (2), pp. 109-117.

LUCIO, I.A. y GUTIÉRREZ, J.J. (2011): "La ciencia del paisaje, un criterio de intervención y ordenación de las ciudades. Una propuesta de actuación sobre la vialidad solidaridad las torres, ciudad de Toluca México", Quivera. Revista de estudios urbanos, regionales, territoriales, ambientales y sociales, vol. 13 (1), Universidad Autónoma del Estado de México, Toluca, México, pp. 156-166.

MATEO, J. (1991) Geoecología de los Paisajes. Universidad de los Andes. Documento curso de Posgrado. Mérida. Venezuela.

MATEO, J. (2008) Geografía de los Paisajes, Segunda Parte. Paisajes naturales, Editorial Universitaria, La Habana, 190 pp.

MATEO, J. (2011) Capítulo (1) de Tesis de Doctorado Facultad de Geografía, Universidad de La Habana Cuba.

MATEO, J. (2013) Teoría y metodología de la geografía, Ministerio de Educación Superior Universidad de la Habana, Facultad de Geografía, Cuba. 273 pp.

MATEO, J., DA SILVA, V. y BRITO, A.P. (1994): Analise da paisage como base para estrategio de Organizacao Geoambiental: Corumbatai, cspl Colectario 004 Planeamiento Ambiental, Universidad de São Paulo, Brasil, pp. 57-105. 
RIVERA, J.A. (2013): "Proceso de urbanización en Pereira y agentes urbanos en Pereira, Colombia: Desigualdad social, fragmentación espacial y conflicto ambiental, 19902012”, Tesis de doctorado_ cap. 7, Universidad de Barcelona, España, pp. 162-178.

SALICHTCHEV, K. (1979): Cartografía. La Habana, Cuba.

SALINAS, E. y PÉREZ, L. (2011): "Procesos urbanos recientes en el Área Metropolitana de Concepción: transformaciones morfológicas y tipologías de ocupación", Revista de Geográfica Norte Grande, n 49, pp. 79-97.

SALOM, J. y ALBERTOS, J.M. (2014): "Delimitation and characterization of new urban spaces in Valencia", Boletín de la Asociación de Geógrafos Españoles, n 64, pp. 433-436.

SOCHAVA, V.S. (1972): "The study of geosystems: the current stage in complex Geography”, in Papers of the 22nd International Geographical Congress, Canadá, pp. 38-57.

SOCHAVA, V.S. (1978): Introducción al estudio geosistémico, Ed. Nauka, Novosibirsk.

SOLNTSEV, N.A. (1948): "El paisaje geográfico natural y algunas de sus regularidades generales", en Trabajos de la segunda reunión de geógrafos soviéticos, (traducido por Prof. Dr. Mateo), Moscú, pp. 53-57.

TURNER, M., GARDNER, R. y O'Neill, R. (2001): Landscape ecology in theory and practice: pattern and process, Springer, New York, Estados Unidos de América.

VIEYRA, A. y LARRAZÁBAL, A. (2014): Urbanización, Sociedad y Ambiente, experiencias en ciudades medias, Morelia, México.

ZULUAGA, G.P. (2005): "Dinámicas Territoriales en fronteras rural-urbana en el corregimiento de Santa Elena", Tesis de Maestría, Universidad Nacional de Colombia, escuela del Hábitat-Facultad de Arquitectura, Medellín, Disponible en: http://www.bdigital.unal. edu.co/5019/1/43030944-2005.pdf 
